\title{
Shear wave elastography parameters of normal soft tissues of the neck
}

\author{
Jan Herman', Zuzana Sedlackovab, Jaromir Vachutkac, Tomas Furst' ${ }^{b}$, Richard Salzmann, Jaroslav Vomacka ${ }^{\mathrm{b}}$
}

\begin{abstract}
Background. Shear wave elastography is a relatively new method of quantitative measurement of tissue elasticity. Assuming that malignant lesions are stiffer than benign ones, elastography may provide supplementary information for their discrimination. However, potential confounding factors impacting tissue stiffness should be investigated first. Aims. The objective of this study was to measure the stiffness of selected tissues of the head and neck in a normal population and to evaluate its relationship to age, sex, and body mass index.

Methods. Stiffness of the thyroid, submandibular and parotid glands, masseter and sternocleidomastoid muscles, and cervical lymph nodes was measured bilaterally in 128 healthy volunteers ( 83 female and 45 male). At least 20 subjects in each decade of life (20-29, 30-39..., 70+) were enrolled. Shear wave elastography was performed by a single radiologist in all the subjects. The stiffnesses obtained were correlated with age, sex, and body mass index.

Results. The mean stiffness was $9.5 \pm 3.6 \mathrm{kPa}$ for the thyroid, $9.5 \pm 4.6 \mathrm{kPa}$ for the lymph node, $11.0 \pm 3.4 \mathrm{kPa}$ for the submandibular gland, $9.0 \pm 3.5 \mathrm{kPa}$ for the parotid gland, $9.9 \pm 4.1 \mathrm{kPa}$ for the sternocleidomastoid, and $10.0 \pm 4.3 \mathrm{kPa}$ for the masseter muscle. A slight general decrease in stiffness with increasing age was found. BMI and weight had a small impact on the minimum and maximum stiffness values. The sex of the subject did not affect elasticity.

Conclusion. The mean stiffness of healthy head and neck organs has a relatively narrow distribution around $11 \mathrm{kPa}$. The changes of stiffness with age, BMI, and weight that were identified are too small to have clinical impact.
\end{abstract}

Key words: elastography, head, lymph node, masseter, neck, parotid, shear wave, sternocleidomastoid, thyroid, ultrasound

Received: February 14, 2017; Accepted: May 4, 2017; Available online: May 25, 2017

https://doi.org/10.5507/bp.2017.024

${ }^{a}$ Department of Otorhinolaryngology, Faculty of Medicine and Dentistry, Palacky University Olomouc and University Hospital Olomouc, Czech Republic

${ }^{b}$ Department of Radiology, Faculty of Medicine and Dentistry, Palacky University Olomouc and University Hospital Olomouc, Czech Republic 'Department of Medical Biophysics, Faculty of Medicine and Dentistry, Palacky University Olomouc, Czech Republic Corresponding author: Richard Salzman, e-mail: rikisali@gmail.com

\section{INTRODUCTION}

Inflammatory as well as neoplastic alterations of soft tissues are associated with changes in their elasticity $^{1}$. Therefore, elasticity assessment is considered to be a very valuable diagnostic tool in differential diagnosis. Traditionally, palpation has been used to evaluate tissue rigidity and/or elasticity. However, this simple classical method is highly subjective and its use is limited to superficially located structures. The applicability of magnetic resonance elastography in various organs is currently under investigation ${ }^{2}$. Ultrasound elastography represents a modern, rapidly growing field of soft tissue imaging. Shear wave elastography (SWE) measures the velocity of shear waves that are induced by so-called push pulses elicited by the ultrasound probe and tracked by standard ultrasound waves (acoustic radiation force impulse - ARFI SWE, in $\mathrm{m} / \mathrm{s}$ ). Alternatively, Young's elastic modulus, which can be calculated from the velocity of the shear waves (supersonic SWE, in $\mathrm{kPa}$ ), is being used. Shear wave elastography is believed to be operator independent and reproducible ${ }^{3}$. The basic principles and head and neck clinical applications of elastography were described elsewhere ${ }^{1,4,5}$.
Ultrasound elastography, especially SWE, has become a recognized diagnostic tool in the assessment of the morphological character of thyroid ${ }^{6}$, breast $^{7}$, liver $^{8}$, and prostate ${ }^{9}$ lesions. It is used mostly for differentiation of benign from malignant tumors, with the latter being considered more rigid (less elastic) (ref. ${ }^{1,4,5}$ ). In order to establish cut-off limits for discriminating benign from malignant lesions, knowledge of their elasticity values and that of their healthy tissue counterparts is necessary. Up to now, the effect of sex, age and BMI on tissue stiffness was not thoroughly studied. That is why we address this issue in the present paper.

Our literature review identified only one study using supersonic shear wave elastography in head and neck tissues (namely thyroid, submandibular and parotid glands, and masseter muscle). It revealed that the mean elasticity of these tissues was quite uniform (approximately $11 \mathrm{kPa} \pm 3 \mathrm{kPa})\left(\right.$ ref. $\left.^{3}\right)$. We believe that confirmation of these results and measurements of the elasticity of other tissues in this anatomic area, namely the sternocleidomastoid muscle and lymph nodes is essential as is the investigation of the effect of age, sex, and BMI on the elasticity of these organs. 


\section{METHODS}

The study was approved by the ethics review board of our institution on 16 December 2013 (reference number 153/13). An informed written consent was obtained from all the volunteers. The study was conducted in accordance with the Helsinki Declaration.

\section{Subjects}

A total of 176 volunteers with no known history of head and neck disease (affecting the thyroid or salivary glands) were recruited from the hospital staff, their family members, and random patients with irrelevant complaints, to undergo an ultrasound examination of the neck. Forty-eight patients were excluded from the study because of incidental pathological findings in the thyroid gland. These were later confirmed to be benign nodules (42 cases), chronic inflammation ( 4 cases), and papillary carcinoma ( 2 cases). The remaining 128 subjects were enrolled in the study.

\section{Population characteristics}

Age and sex were recorded for each subject. BMI was calculated in all but two subjects who refused to provide us with relevant information. The age of the subjects varied from 21 to 91 years old, with an even distribution in the particular decades, thus eliminating potential bias. The mean age was 48.8 years. The mean values of the height, weight, and BMI were $1.7 \mathrm{~m}, 73 \mathrm{~kg}$, and 25.1 , respectively (Table 1).

\section{Ultrasound and Shear wave ultrasound elastographic imaging technique}

After a thorough ultrasonographic examination of the neck, shear wave elastography of the thyroid, submandibular and parotid glands, cervical lymph nodes, masseter and sternocleidomastoid muscles was performed bilaterally using the SuperSonic Imagine Aixplorer ultrasound machine, with a compact linear array transducer SL 15-4 MHz. The measurements were obtained in the su- pine position. The tip of the transducer was covered with a layer of ultrasound gel of approximately $5 \mathrm{~mm}$ width and placed on the skin without compressing the tissue. It was kept still for a few seconds to obtain SWE images of adequate quality. All measurements were performed by a single (right-handed) radiologist sitting to the right of the subject examined each time. For each measurement, the minimum (i.e. the minimum stiffness in the selected region), maximum (i.e. the maximum stiffness in the region), and mean elasticity values were obtained on a frozen image by placing a circular region of interest (ROI) as large as possible, but avoiding the adjacent structures.

\section{Statistical methods}

The shear wave parameters (in $\mathrm{kPa}$ ) of the particular tissues were compared by means of the Mann-Whitney test (for two samples, e.g. the parotid and submandibular gland) or the Kruskal-Wallis test (for multiple samples, i.e. all the tissues measured among each other). The dependence of all the obtained shear wave parameters on sex and laterality (left vs. right side) was assessed by means of the Mann-Whitney test and the dependence on age, height, weight, and BMI by non-parametric (Spearman) correlation. All the tests were performed in STATISTICA, version 10.0, Statsoft Inc, Tulsa, CA, and MatLab R2013b, The MathWorks Inc., Natick, MA. The level of significance was always set at 0.05 .

\section{RESULTS}

In general, the shear wave parameters of the tissues measured ranged between 0.1 (the lower limit of the device) and $54 \mathrm{kPa}$. Most mean values of all the organs $(90.2 \%)$ were lower than $15 \mathrm{kPa}$. The mean stiffnesses obtained were $9.46 \pm 3.6 \mathrm{kPa}$ for the thyroid, $9.46 \pm 4.6 \mathrm{kPa}$ for the lymph node, $11.01 \pm 3.4 \mathrm{kPa}$ for the submandibular gland, $8.95 \pm 3.5 \mathrm{kPa}$ for the parotid gland, $9.89 \pm 4.1 \mathrm{kPa}$ for the sternocleidomastoid muscle, and $10.04 \pm 4.3 \mathrm{kPa}$ for the masseter muscle (Table 2).

Table 1. Basic characteristics of the study population.

\begin{tabular}{lrrrrrr}
\hline & $\mathrm{n}$ & Mean & Median & \multicolumn{1}{c}{ Min } & \multicolumn{1}{c}{ Max } & \multicolumn{1}{c}{ Std } \\
\hline Age [years] & 128.00 & 48.82 & 47.50 & 21.00 & 91.00 & 18.29 \\
Height [m] & 126.00 & 1.70 & 1.70 & 1.48 & 1.95 & 0.09 \\
Weight [kg] & 127.00 & 72.98 & 72.00 & 42.00 & 126.00 & 15.47 \\
BMI [kg/m $\left.{ }^{2}\right]$ & 126.00 & 25.11 & 24.38 & 15.06 & 47.42 & 4.87 \\
\hline
\end{tabular}

Table 2. Stiffness of the of head and neck tissues in $\mathrm{kPa}$.

\begin{tabular}{lccccc}
\hline & Mean & Median & $\begin{array}{c}\text { Standard } \\
\text { Deviation }\end{array}$ & 5\% quantile & $95 \%$ quantile \\
\hline Thyroid gland & 9.46 & 9.1 & 3.57 & 4.63 & 16.2 \\
Lymph node & 9.64 & 9.15 & 4.62 & 2.5 & 17.5 \\
Submandibular gland & 11.01 & 10.5 & 3.36 & 6.5 & 17.44 \\
Parotid gland & 8.95 & 8.1 & 3.5 & 4.33 & 15.34 \\
Sternocleidomastoid muscle & 9.89 & 9.3 & 4.11 & 3.9 & 17.98 \\
Masseter muscle & 10.04 & 9.85 & 4.33 & 4.1 & 18.54 \\
\hline
\end{tabular}




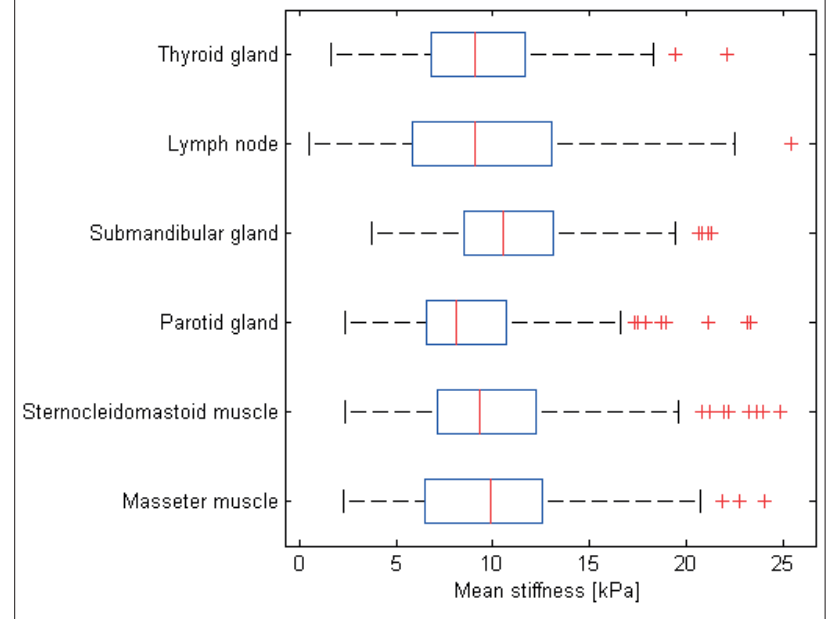

Fig. 1. Comparison of mean stiffness of individual organs.

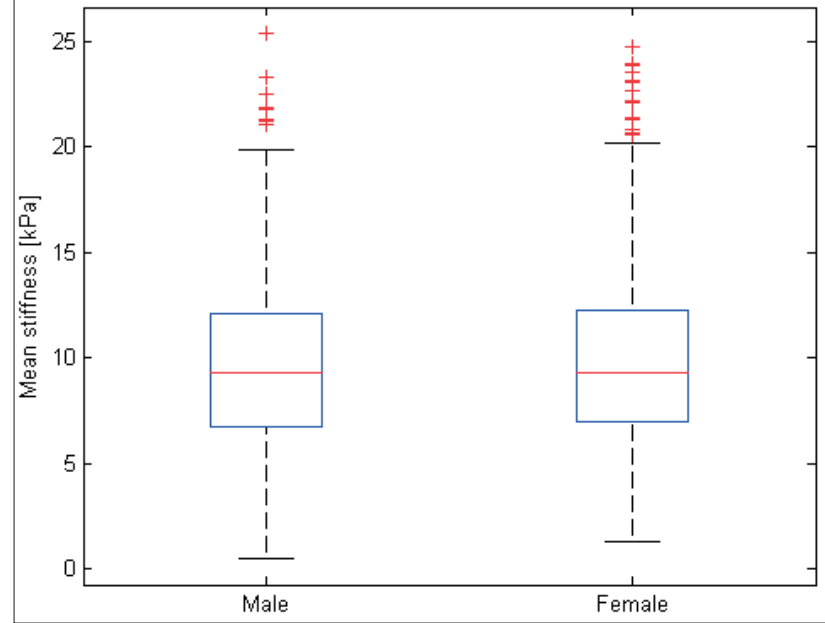

Fig. 2. Comparison of mean stiffness in all organs in males and females.

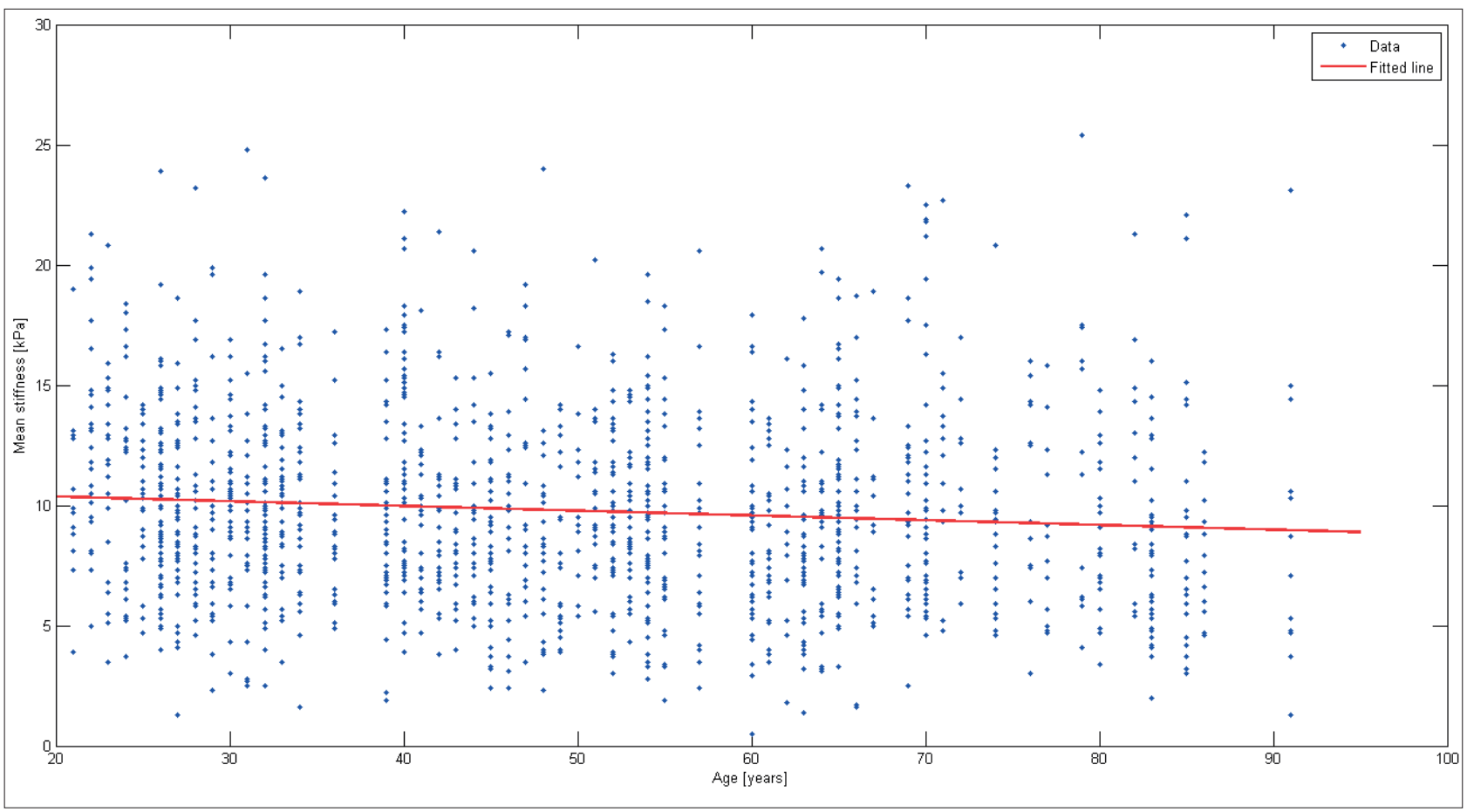

Fig. 3. Effect of age on stiffness of all the tissues studied, scatter plot, decreasing line of the slope -0.020 [kPa/year], $95 \%$ confidence interval for the slope: $[-0.031,-0.009]$

The mean stiffness differed significantly among the tissues studied (Kruskal-Wallis, $P<0.001$ ) (Fig. 1).

\section{The effect of sex}

We found no systematic effect of sex on the minimum, maximum or mean stiffness in any particular organ, and neither generally (Mann-Whitney, $P=0.38$ ) (Fig. 2).

\section{The effect of age}

Tissue stiffness generally decreased with increasing age (Fig. 3). The correlation coefficient (c) between age and mean stiffness was -0.10 . This effect, reaching significance for both masseter muscles ( $\mathrm{c}=-0.25, P=0.005$ on the left and $\mathrm{c}=-0.24, P=0.006$ on the right) and the left but not right sternocleidomastoid muscle $(\mathrm{c}=-0.2$,
$P=0.03$ on the left and $\mathrm{c}=-0.1, P=0.24$ on the right), was systematically found in most tissues studied. This effect was generally present also for the minimum values of tissue stiffness and significant for both the muscles (sternocleidomastoid and masseter). In stiffness maxima, most correlations were negative, but the effect was not systematic. A significant decrease was found in the masseter and sternocleidomastoid muscles, but only on the left side ( $\mathrm{c}=-0.27, P=0.002$ and $\mathrm{c}=-0.19, P=0.04$, respectively).

\section{The effect of BMI (and weight)}

Generally, there was no effect of BMI on the mean stiffness values. However, the minima decreased with increasing BMI $(\mathrm{c}=-0.20)$. This effect reached significance for all tissues on both sides, except for the parotid 
Table 3. Qualitative summary of the correlation of elastographic parameters with age, height, weight, and BMI.

\begin{tabular}{|c|c|c|c|c|}
\hline & Age & Height & Weight & BMI \\
\hline Minimal stiffness & $\searrow$ & n.e. & $\searrow$ & $\searrow$ \\
\hline Mean stiffness & $\searrow$ & n.e. & n.e. & n.e. \\
\hline Maximal stiffness & n.e. & n.e. & n.e. & n.e. \\
\hline
\end{tabular}

n.e. stands for 'no effect'; $\searrow$ means that the parameter decreases with increasing age, weight, BMI (details in the text)

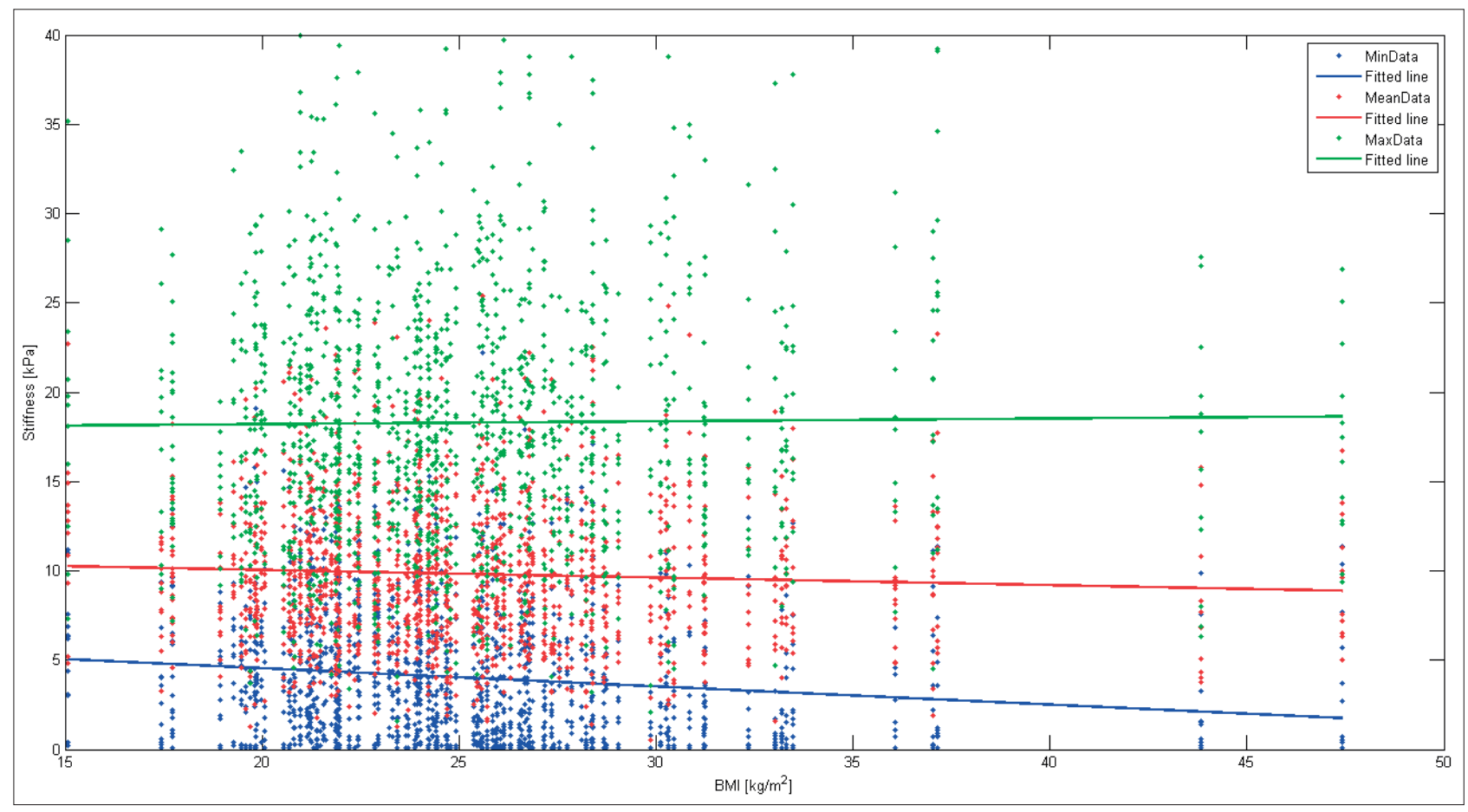

Fig. 4. Effect of BMI on maximum, mean, and minimum stiffness.

The slope of the line for maxima (green): $0.016\left[\mathrm{kPa} \mathrm{m}^{2} / \mathrm{kg}\right], 95 \%$ confidence interval: $[-0.061,+0.093]$, slope of the line for mean (red): -0.043016 [kPa m²/kg], 95\% confidence interval: [-0.087, +0.002], slope of the line for minima (blue): $-0.102016[\mathrm{kPa} \mathrm{m} /$ $\mathrm{kg}$ ], $95 \%$ confidence interval: $[-0.139,-0.065]$.

( $\mathrm{c}=-0.16, P=0.07$ on the right and $\mathrm{c}=-0.07, P=0.45$ on the left) and the submandibular gland ( $P=0.16$ and $P=0.48$ on the left and right sides, respectively) (Fig. 4). In the case of stiffness maxima, the majority of the correlation coefficients were positive. However, unlike in the case of minima, none of the correlation coefficients reached statistical significance here.

We decomposed BMI into weight and height $\left(\mathrm{BMI}=\right.$ weight $[$ in $\mathrm{kg}] /$ height $\left.[\text { in } \mathrm{m}]^{2}\right)$. The minima of stiffness generally decreased with increasing weight (all the correlation coefficients were negative and most of them significant). We found no correlation of the stiffness minima with height (the correlation coefficients had no systematic sign and none of them reached significance).

The correlations among the parameters studied are shown in Table 3.

\section{The effect of laterality}

Statistical analysis of our results demonstrated systematically lower stiffness of all the organs on the left side. This was true for their mean, minimum, and maximum values $(P<0.001$, Mann-Whitney). The effect was significant in all the tissues measured, with the exception of lymphatic nodes and the sternocleidomastoid muscle (Fig. 5).

\section{DISCUSSION}

Ultrasound elastography is a booming field in tissue imaging. Initial clinical experience, dealing with prostate lesions, was published in 2010 (ref. ${ }^{10}$ ). SWE is being used in assessing liver fibrosis, the median stiffness values of which were demonstrated to rise with its more advanced stages (from $6.2 \mathrm{kPa}$ in stage $0-1$ to $15.6 \mathrm{kPa}$ in stage 5 ) (rRef. ${ }^{11}$ ). Very encouraging results were obtained in breast masses. SWE revealed a sensitivity and specificity in the discrimination between benign and malignant lesions of $97 \%$ and $95 \%$, respectively. For the assessment of the dignity of these masses, the optimal cut-off mean, maximum, and minimum values were stated to be $45.7 \mathrm{kPa}, 54.3 \mathrm{kPa}$, and $37.1 \mathrm{kPa}$, respectively ${ }^{12}$. Experience with SWE in prostate lesions has also been promising. A study of Barr et al. 
using a cut-off value of $37 \mathrm{kPa}$ for the discrimination of benign from malignant masses reached a negative predic-

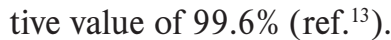

In the head and neck setting, elastography (both shear wave and strain) is primarily used in thyroid pathology, with our Medline search revealing more than 40 original studies. Cut-off values between benign and malignant nodules as summarized in a meta-analysis varied from 34.5 to $90.3 \mathrm{kPa}\left(\right.$ ref. $\left.^{6}\right)$.

Only two studies using SWE for the discrimination of benign from malignant lesions of cervical lymph nodes have been published so far. Bhatia et al. found $41.9 \%$ sensitivity and $100 \%$ specificity with an optimal cut-off of $30.2 \mathrm{kPa}\left(\right.$ ref. $^{14}$ ). Choi et al., using cut-off values of $19.4 \mathrm{kPa}$, reported a sensitivity and specificity of $95 \%$ and $97 \%$, respectively ${ }^{15}$.

The contribution of ultrasound elastography in salivary gland masses was questioned by Bhatia et al., because of significant overlap of median shear moduli of malignant affections $(13.5 \mathrm{kPa})$ and of the benign lesions, represented mainly by pleomorphic adenomas $(18.3 \mathrm{kPa})$ $\left(\right.$ ref. $\left.^{16}\right)$.

In general, information regarding the stiffness of healthy tissues is scarce. The mean values of stiffness of a healthy liver, glandular, and fatty tissue of the breast as measured in healthy volunteers were $4.64 \pm 1.18 \mathrm{kPa}^{17}$, $11.3 \pm 5.3 \mathrm{kPa}$, and $9.2 \pm 4.5 \mathrm{kPa}$, respectively ${ }^{18}$. The mean values in the prostate were $4.1 \pm 0.8 \mathrm{kPa}$ and $9.9 \pm 0.9 \mathrm{kPa}$ in the peripheral and central zones, respectively ${ }^{10}$.

To the best of our knowledge, only one paper assessing elasticity values using SWE with results in kilopascals in healthy organs of the head and neck region has been published so far $^{3}$. In this study, the mean stiffnesses of the thyroid, submandibular gland, parotid gland, and the masseter muscle were $10.97 \pm 3.1 \mathrm{kPa}, 10.92 \pm 3.1 \mathrm{kPa}$, $10.38 \pm 3.5 \mathrm{kPa}$, and $10.4 \pm 3.7 \mathrm{kPa}$, respectively. The above values are in concert with the results obtained in our study dealing with the same tissues. Moreover, we found a comparable elasticity in cervical lymph nodes and sternocleidomastoid muscle.

Arda et al. stated that age and sex had no significant impact on the elasticity of the head and neck organs ${ }^{3}$. Similarly, we failed to confirm a correlation between sex and elasticity. On the other hand, we found a negative correlation between age and the minimum and mean stiffness of the tissues. These results would not be surprising in the parotid gland, the age-related atrophy of which is associated with an increase in its fatty component. However, in the submandibular gland, the interpretation of the results would be obscure, considering the tendency of this gland to show fibrotic atrophy. Anyway, the decrease in stiffness was statistically significant only in the muscles where plain atrophy is the most probable type of degeneration, and this does not explain the results.

We found no paper evaluating the influence of BMI on elasticity. In the present study, the minima of stiffness generally decreased significantly with increasing BMI. Surprisingly, for the maxima, the opposite effect was present, meaning that the range of stiffness (i.e. the difference

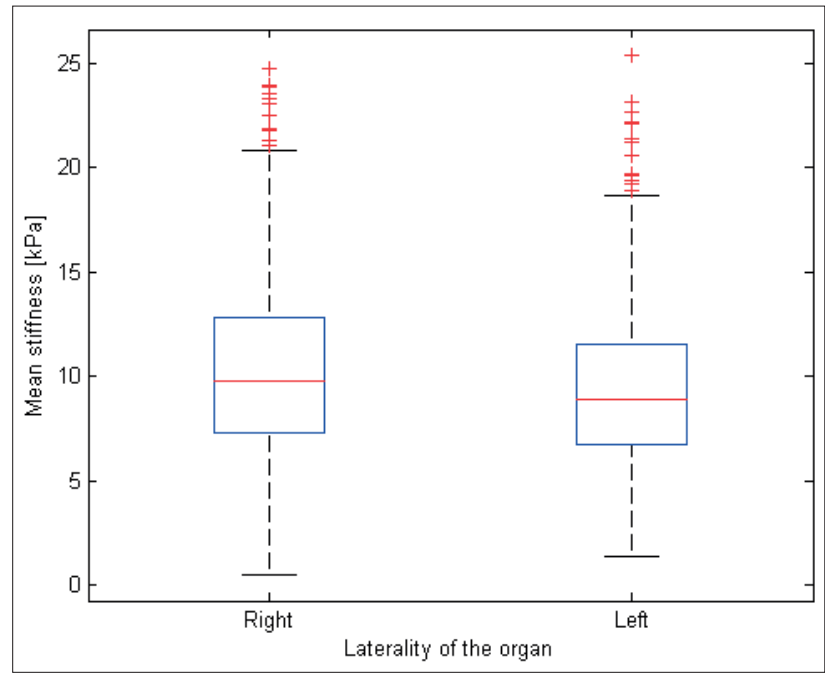

Fig. 5. Comparison of mean stiffness in all organs on contralateral sides.

between the maximum and minimum stiffness) increased with BMI. The increase of maxima was statistically significant only in the thyroid and sternocleidomastoid muscle, not generally. We cannot offer any plausible explanation for these phenomena.

When evaluating weight and height as components of BMI, the effect of the former was the same as that of BMI - the minima of stiffness generally decreased with increasing weight. Interestingly, there was no correlation of the stiffness minima with height. Thus, the decreasing minimum stiffness was associated with weight only.

In general, the mean stiffness of the right side significantly exceeded that of the left (Fig. 2). We consider these results to be artificial, since the examiner was constantly positioned on the right side of the subjects examined, thereby applying higher hand pressure during the scanning of ipsilateral tissues. Different pressure might theoretically influence the results of B-mode sonography as well, for example causing a variation in the size of the lesion measured. However, the above-mentioned side differences, even though statistically significant, are too small to have a real clinical impact on SWE discrimination of normal from pathologically changed tissues.

The narrow distribution of mean stiffness of healthy head and neck tissues is highly promising for the possibility of establishing a cut-off value between normal and pathological findings.

The stiffness of altered (especially malignant) tissues usually reaches tens of kilopascals ${ }^{5}$, while that of their healthy counterparts is markedly lower, varying slightly around $11 \mathrm{kPa}$, as demonstrated in our study and that of Arda et al. ${ }^{3}$. The significant age and side-related changes of stiffness were in the order of units of kilopascals. For this reason, we consider them to be clinically irrelevant.

Nonetheless, we assume that further studies are needed to verify the level of influence of age and side on elastography results, and this effect should always be considered. 


\section{CONCLUSION}

The mean stiffness of healthy head and neck organs has a relatively narrow distribution around $11 \mathrm{kPa}$. We failed to demonstrate differences in stiffness between the sexes. We found a slight general decrease in stiffness with increasing age. BMI and weight had a small impact on the minimum and maximum stiffness values. A significant difference between the sides examined was noted.

The clinical impact of all the above mentioned factors affecting elasticity is probably minimal.

Acknowledgement: This work was supported by the AZV MZ ČR 16-31881A grant.

Author contributions: JH: manuscript writing, volunteers recruitment; ZS: measurements; JV: study design, technical counseling; TF: statistical analysis; RS: study design, manuscript revisions; JV: study design.

Conflict of interest statement: Authors declare there are no conflicts of interest regarding the publication of this article.

\section{REFERENCES}

1. Bhatia KS, Lee YY, Yuen EH, Ahuja AT. Ultrasound elastography in the head and neck. Part I. Basic principles and practical aspects. Cancer Imaging 2013;22,13(2):253-9.

2. Arda K, Ciledug N, Aktas E, Aribas BK, Köse K. Quantitative assessment of normal soft-tissue elasticity using shear-wave ultrasound elastography. AJR Am J Roentgenol 2011;197(3):532-6.

3. Bhatia KS, Lee YY, Yuen EH, Ahuja AT. Ultrasound elastography in the head and neck. Part II. Accuracy for malignancy. Cancer Imaging 2013;22,13(2):260-76.

4. Heřman J, Heřmanová Z, Salzman R, Vomáčka J, Stárek I. Ultrazvuková elastografie a její využití v oblasti hlavy a krku. Čas Lék čes 2015;154:222-6.
5. Zhang B, Ma X, Wu N, Liu L, Liu X, Zhang J, Yang J, Niu T. Shear wave elastography for differentiation of benign and malignant thyroid nodules: a meta-analysis. J Ultrasound Med 2013;32(12):2163-9.

6. Gong X, Xu Q, Xu Z, Xiong P, Yan W, Chen Y. Real-time elastography for the differentiation of benign and malignant breast lesions: $a$ meta-analysis. Breast Cancer Res Treat 2011;130(1):11-8.

7. Friedrich-Rust M, Ong MF, Martens S, Sarrazin C, Bojunga J, Zeuzem S, Herrmann E. Performance of transient elastography for the staging of liver fibrosis: a meta-analysis. Gastroenterol 2008;134(4):96074.

8. Cochlin DL, Ganatra RH, Griffiths DFR. Elastography in the detection of prostatic cancer. Clin Radiol 2002;57(11):1014-20.

9. Manduca A, Oliphant TE, Dresner MA, Mahowald JL, Kruse SA, Amromin E, Felmlee JP, Greenleaf JF, Ehman RL. Magnetic resonance elastography: non-invasive mapping of tissue elasticity. Med Image Anal 2001;5(4):237-54.

10. Zhai L, Madden J, Foo WC, Mouraviev V, Polascik TJ, Palmeri ML, Nightingale KR. Characterizing stiffness of human prostates using acoustic radiation force. Ultrason imaging 2010;32.4:201-13.

11. Ferraioli G, Tinelli C, Dal Bello B, Zicchetti M, Filice G. Accuracy of realtime shear wave elastography for assessing liver fibrosis in chronic hepatitis C: A pilot study. Hepatology 2012;56(6):2125-33.

12. Chang JY, Moon JH, Koh SJ, Park SY, Lee KS. Clinical application of shear wave elastography (SWE) in the diagnosis of benign and malignant breast diseases. Breast Cancer Res Treat 2011;129(1):89-97.

13. Barr RG, Memo R, Schaub CR. Shear wave ultrasound elastography of the prostate: initial results. Ultrasound Q 2012;28(1):13-20.

14. Bhatia KS, Cho CC, Tong CS, Yuen EH, Ahuja AT. Shear wave elasticity imaging of cervical lymph nodes. Ultrasound Med Biol 2012;38(2):195-201.

15. Choi YJ, Lee JH, Lim HK, Kim SY, Han MW, Cho KJ, Baek JH. Quantitative shear wave elastography in the evaluation of metastatic cervical lymph nodes. Ultrasound Med Biol 2013;39(6):935-40.

16. Bhatia KS, Cho CC, Tong CS, Lee YY, Yuen EH, Ahuja AT. Shear wave elastography of focal salivary gland lesions: preliminary experience in a routine head and neck US clinic. Eur Radiol 2012;22:957-65.

17. Ferraioli G, Tinelli C, Zicchetti M, Above E, Poma G, Di Gregorio M, Filice $C$. Reproducibility of real-time shear wave elastography in the evaluation of liver elasticity. Eur J Radiol 2012;81(11):3102-06.

18. Rzymski, Paweł, Skórzewska A, Skibińska-Zielińska M, Opala T. Factors influencing breast elasticity measured by the ultrasound Shear Wave elastography-preliminary results. Arch Med Sci 2011;7(1):127-33. 